\title{
Crystal Structure of 4,6-Dimethyl-2-\{4-[(2-pyrimidyl)piperazin-1-yl]- methyl\}isothiazolo[5,4-b]pyridin-3(2H)-one
}

\author{
Zbigniew KarCZMARZYK ${ }^{* \dagger}$ and Wiesław MALINKA** \\ *Department of Chemistry, University of Podlasie, ul. 3 Maja 54, 08-110 Siedlce, Poland \\ **Department of Chemistry of Drugs, Medical University, ul. Tamka 1, 50-137 Wrocław, Poland
}

\begin{abstract}
The title compound, $\mathrm{C}_{17} \mathrm{H}_{20} \mathrm{~N}_{6} \mathrm{OS}$, crystallizes in the triclinic system, space group $P \overline{1}$, with cell constants $a=6.166(1) \AA, b$ $=8.874(2) \AA, c=16.850(3) \AA, \alpha=80.89(3)^{\circ}, \beta=86.71(3)^{\circ}, \gamma=73.35(3)^{\circ}$ and $Z=2$. The piperazine ring adopts a chair conformation. A strong conjugation effect of the lone pair of the tertiary $\mathrm{N}$ atom with the $\pi$-electron system of the pyrimidine ring is observed. The molecular packing is influenced by the weak $\mathrm{C}-\mathrm{H} \cdots \mathrm{O}$ intermolecular hydrogen bonds.
\end{abstract}

(Received October 12, 2005; Accepted January 10, 2006; Published on web March 13, 2006)

Due to the considerable analgesic potency exhibited by some 2-\{4-[(substitutedphenyl)piperazin-1-yl]methyl $\}$ isothiazolopyridins of the Mannich base, a series of related compounds with a side chain, which represent a marked departure in the substructure of 4-arylpiperazine [i.e. $\mathrm{N}$-(2pyrimidinyl)piperazine, $\quad N$-methyl- $N^{\prime}$-phenylethylenediamine, 1,2,3,4-tetrahydro- $\beta$-carboline, $N$-cyclohexylpiperazine] was synthesized. ${ }^{1,2}$ These compounds were evaluated concerning the toxicity and analgesic action in order to extend the structure-activity (SAR) studies and to find a correlation between the biological activity and the molecular structure within the investigated series and their non-4-arylpiperazine analogues. As a part of these investigations, in this paper we report on the results of an X-ray structure determination of the title 4,6-dimethyl-2-\{4-[(2-pyrimidyl)-piperazin-1-yl]methyl $\}$ isothiazolo[5,4-b]pyridin-3(2H)-one (Fig. 1), which proved to be inactive as an analgesic agent under pharmacological screening. This compound was prepared in a Mannich reaction from 4,6dimethylisothiazolo-[5,4-b]pyridin-3(2H)-one, formaldehyde and commercially available $N$-(2-pyrimidyl)piperazine. ${ }^{2}$ The identity of the investigated compound was established by its IR, ${ }^{1} \mathrm{H}$ NMR, elementary analysis, and was finally confirmed by an $\mathrm{X}$-ray analysis.

Colorless plate crystals suitable for X-ray diffraction analysis were grown by slow evaporation from an 1-heptane solution. $\mathrm{X}$-ray data were collected by graphite-monochromatized $\mathrm{Cu} K_{\alpha}$ radiation at $293 \mathrm{~K}, \omega$ scans. The structure was solved by direct

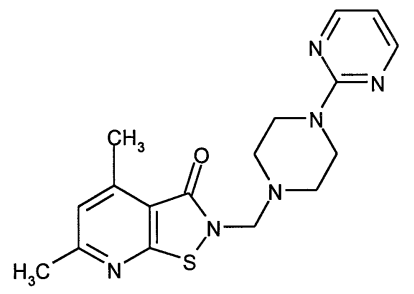

Fig. 1 Structural chemical diagram.

$\dagger$ To whom correspondence should be addressed.

E-mail: kar@ap.siedlce.pl methods and refined by a full-matrix least-squares method with anisotropic temperature factors for non- $\mathrm{H}$ atoms. All $\mathrm{H}$ atoms were treated as riding, with $\mathrm{C}-\mathrm{H}$ distances of $0.93 \AA$ (aromatic), $0.96 \AA\left(\mathrm{CH}_{3}\right)$ and $0.97 \AA\left(\mathrm{CH}_{2}\right)$ and $U_{\text {iso }}=1.5 U_{\mathrm{eq}}(\mathrm{C})$. Details of the crystal data and a structure refinement and selected geometrical parameters are given in Tables 1, 2 and 3. A view of the molecule with numbering of the atoms is shown in Fig. 2.

The bond lengths, angles and planarity of the rings in the isothiazolopyridine part of the title compound are very similar to those reported for other related structures. ${ }^{3,4}$ The apparent asymmetry in the values of the exocyclic bond angles at $\mathrm{C} 3$ [122.6(5) and $\left.128.8(5)^{\circ}\right]$ and N2 [118.1(4) and 124.4(4) $\left.{ }^{\circ}\right]$ is due to a steric effect of the bulky methyl, carbonyl and methylene

Table 1 Crystal and experimental data

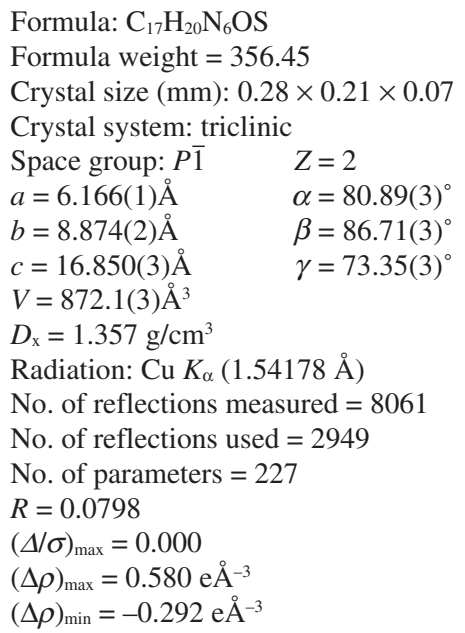

Measurement: Bruker SMART APEX CCD

Program system: Bruker SMART

Structure determination: direct methods (SIR92)

Refinement: full matrix least-squares (SHELXL97)

CCDC 294272 contains the supplementary crystallographic data for this paper. These data can be obtained free of charge from The Cambridge Crystallographic Data Centre via www.ccdc.cam.ac.uk/data_request/cif. 
Table 2 Final atomic coordinates $\left(\times 10^{4}\right)$ and equivalent isotropic temperature factors $\left(\AA^{2} \times 10^{3}\right)$

\begin{tabular}{lcrrr}
\hline Atom & $x$ & $y$ & $z$ & $U_{\text {eq }}{ }^{*}$ \\
\hline S1 & $2976(2)$ & $4622(1)$ & $2375(1)$ & $62(1)$ \\
O3 & $4467(7)$ & $783(4)$ & $1468(2)$ & $73(1)$ \\
N2 & $4365(7)$ & $2711(5)$ & $2231(2)$ & $61(1)$ \\
N7 & $-832(7)$ & $5948(5)$ & $1518(2)$ & $62(1)$ \\
N21 & $6440(7)$ & $2571(5)$ & $3377(2)$ & $58(1)$ \\
N24 & $7099(8)$ & $2836(7)$ & $4983(3)$ & $73(1)$ \\
N32 & $6444(8)$ & $1938(6)$ & $6304(3)$ & $70(1)$ \\
N36 & $9779(7)$ & $2734(6)$ & $5895(3)$ & $70(1)$ \\
C3 & $3510(9)$ & $2094(6)$ & $1666(3)$ & $59(1)$ \\
C4 & $-209(10)$ & $3071(6)$ & $857(3)$ & $63(1)$ \\
C5 & $-2063(10)$ & $4400(7)$ & $694(3)$ & $71(1)$ \\
C6 & $-2312(9)$ & $5785(6)$ & $1011(3)$ & $66(1)$ \\
C8 & $954(8)$ & $4657(6)$ & $1680(3)$ & $56(1)$ \\
C9 & $1383(9)$ & $3238(5)$ & $1369(3)$ & $56(1)$ \\
C10 & $-5(12)$ & $1572(7)$ & $520(4)$ & $81(2)$ \\
C11 & $-4326(11)$ & $7199(7)$ & $808(4)$ & $77(2)$ \\
C12 & $6484(9)$ & $1946(7)$ & $2635(3)$ & $71(1)$ \\
C22 & $5298(9)$ & $1806(7)$ & $4027(3)$ & $65(1)$ \\
C23 & $4922(9)$ & $2714(8)$ & $4734(3)$ & $71(1)$ \\
C25 & $8344(11)$ & $3535(9)$ & $4325(3)$ & $77(2)$ \\
C26 & $8650(9)$ & $2602(8)$ & $3637(3)$ & $70(1)$ \\
C31 & $7789(9)$ & $2488(6)$ & $5753(3)$ & $60(1)$ \\
C33 & $7184(11)$ & $1605(7)$ & $7048(4)$ & $74(2)$ \\
C34 & $9198(10)$ & $1801(7)$ & $7262(3)$ & $72(1)$ \\
C35 & $10419(10)$ & $2368(7)$ & $6651(4)$ & $74(2)$ \\
\hline
\end{tabular}

$U_{\mathrm{eq}}=(1 / 3) \Sigma_{i} \Sigma_{j} U_{i j}\left(a_{i} * a_{j}^{*}\right)\left(\boldsymbol{a}_{i} \cdot \boldsymbol{a}_{j}\right)$.

Table 3 Selected bond distances $(\check{A})$ and angles $\left({ }^{\circ}\right)$

\begin{tabular}{lrlr}
\hline S1-N2 & $1.715(4)$ & N21-C26 & $1.465(6)$ \\
S1-C8 & $1.750(5)$ & N24-C31 & $1.349(7)$ \\
O3-C3 & $1.233(6)$ & N24-C23 & $1.467(6)$ \\
N2-C3 & $1.370(6)$ & N24-C25 & $1.470(6)$ \\
N2-C12 & $1.441(7)$ & C3-C9 & $1.467(7)$ \\
N21-C12 & $1.441(7)$ & C8-C9 & $1.389(7)$ \\
N21-C22 & $1.452(6)$ & & \\
& & & \\
N2-S1-C8 & $89.1(2)$ & C31-N24-C25 & $123.1(4)$ \\
C3-N2-C12 & $124.4(4)$ & C23-N24-C25 & $113.2(4)$ \\
C3-N2-S1 & $117.0(3)$ & O3-C3-N2 & $122.6(5)$ \\
C12-N2-S1 & $118.1(4)$ & O3-C3-C9 & $128.8(5)$ \\
C12-N21-C22 & $113.0(4)$ & N2-C3-C9 & $108.6(4)$ \\
C12-N21-C26 & $114.8(4)$ & C9-C8-S1 & $112.9(4)$ \\
C22-N21-C26 & $110.4(4)$ & C8-C9-C3 & $112.1(4)$ \\
C31-N24-C23 & $123.4(4)$ & & \\
& & & \\
S1-N2-C12-N21 & $30.1(6)$ & N2-C12-N21-C26 & $-149.4(5)$ \\
N2-C12-N21-C22 & $82.8(6)$ & C23-N24-C31-N32 & $3.0(8)$ \\
\hline
\end{tabular}

groups at adjacent positions of the isothiazolopyridine ring. The orientation of the pyrimidylpiperazine substituent in relation to the fused bicyclic system is described by torsion angles S1-N2-C12-N21, N2-C12-N21-C22 and N2-C12-N21-C26 of $30.1(6), 82.8(6)$ and $-149.4(5)^{\circ}$, respectively. The piperazine ring adopts a chair conformation with puckering parameters of $Q=0.575(6) \AA$ and $\theta=176.9(6)^{\circ} .^{5}$ The N21-C12 and N24-C31 bonds occupy equatorial positions, but the angles formed by these $\mathrm{N}-\mathrm{C}$ bonds with a least-squares plane normal of the piperazine ring $\left[82.3(3)^{\circ}\right.$ for $\mathrm{N} 21-\mathrm{C} 12$ and $62.6(4)^{\circ}$ for N24-C31] are significantly different. This is due to a strong conjugation effect of the lone pair at the N24 atom with the $\pi$ electron deficiency system of the pyrimidine ring. The flatness of the pyramidal configuration of N24 with the sum of the bond angles around this atom of $359.7(4)^{\circ}$, the N24-C31 bond length of $1.349(7) \AA$ being significantly shorter than the N21-C12 of

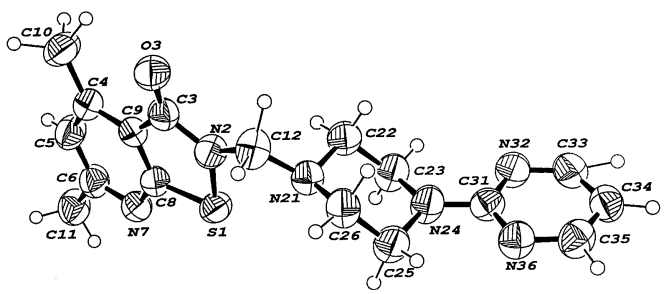

Fig. 2 ORTEP III drawing of the title compound with atom labelling. The thermal ellipsoids are drawn at the $30 \%$ probability level.

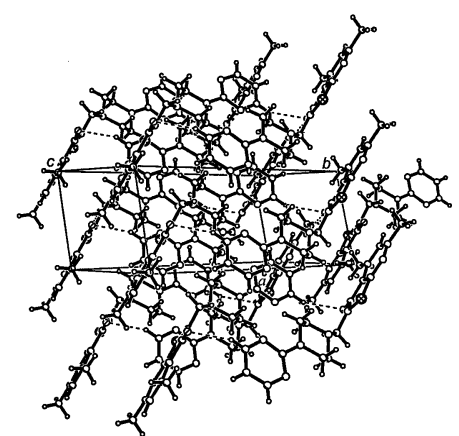

Fig. 3 Packing diagram of the title compound. Dashed lines indicate intermolecular hydrogen bonds.

1.441(7) $\AA$ and the almost co-planar position of the piperazine and pyrimidine rings described by the torsion angle C23-N24-C31-N32 of 3.0(8) ${ }^{\circ}$ are favourable for propagation of this conjugation effect in the pyrimidine ring. The conformation of the pyrimidylpiperazine substituent is

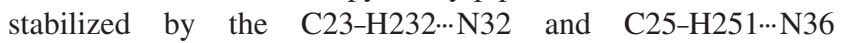
intramolecular hydrogen bonds: $\mathrm{C} 23-\mathrm{H} 232=0.970(6)$, $\mathrm{H} 232 \cdots \mathrm{N} 32=2.351(5), \quad \mathrm{C} 23 \cdots \mathrm{N} 32=2.774(7) \AA$, $\mathrm{C} 23-\mathrm{H} 232 \cdots \mathrm{N} 32=105.6(4)^{\circ}$ and $\mathrm{C} 25-\mathrm{H} 251=0.970(7)$, $\mathrm{H} 251 \cdots \mathrm{N} 36=2.323(5), \quad \mathrm{C} 25 \cdots \mathrm{N} 36=2.755(7) \AA$, $\mathrm{C} 25-\mathrm{H} 251 \cdots \mathrm{N} 36=106.2(4)^{\circ}$. The molecular packing in the crystal (Fig. 3) is influenced by the presence of the weak $\mathrm{C}-\mathrm{H} \cdots \mathrm{O}$ intermolecular hydrogen bonds: $\mathrm{C} 11-\mathrm{H} 113 \cdots \mathrm{O} 3^{(\mathrm{i})}$ $[\mathrm{C} 11-\mathrm{H} 113=0.960(7), \mathrm{H} 113 \cdots \mathrm{O} 3=2.520(4), \mathrm{C} 11 \cdots \mathrm{O} 3=$ $3.401(8) \AA, \mathrm{C} 11-\mathrm{H} 113 \cdots \mathrm{O} 3=152.6(4)^{\circ}$ and (i) $\left.=x-1, y+1, z\right]$ and $\mathrm{C} 33-\mathrm{H} 331 \cdots \mathrm{O}^{(i i)}[\mathrm{C} 33-\mathrm{H} 331=0.930(6), \mathrm{H} 331 \cdots \mathrm{O} 3=$ $2.461(4), \mathrm{C} 33 \cdots \mathrm{O} 3=3.323(7) \AA, \mathrm{C} 33-\mathrm{H} 331 \cdots \mathrm{O} 3=154.2(4)^{\circ}$ and (ii) $=-x+1,-y,-z+1]$.

\section{References}

1. W. Malinka, P. Świątek, B. Filipek, J.Sapa, A. Jezierska, and A. Koll, Farmaco, 2005, 60, 961.

2. W. Malinka, Acta Polon. Pharm. Drug Res., 1991, 48, 19.

3. Z. Karczmarzyk and W. Malinka, Acta Cryst., 1998, C54, 992.

4. Z. Karczmarzyk and W. Malinka, J. Chem. Crystallogr., 2004, 34, 453.

5. D. Cremer and J. A. Pople, J. Am. Chem. Soc., 1975, 97, 1354. 